\title{
Invited review: Dairy intake and bone health: A viewpoint from the state of the art ${ }^{1}$
}

\author{
A. Caroli, ${ }^{2}{ }^{2}$ A. Poli, $†$ D. Ricotta, ${ }^{\star}$ G. Banfi, $\neq$ and D. Cocchi ${ }^{\star} \S$ \\ *Dipartimento di Scienze Biomediche e Biotecnologie, Università degli Studi di Brescia, Viale Europa 11, Brescia, 25123 Italy \\ †Nutrition Foundation of Italy, Viale Tunisia 38, Milan, 20124 Italy \\ fIRCCS Istituto Ortopedico Galeazzi, Via Riccardo Galeazzi 4, Milan, 20161 Italy \\ $\S$ Centro di Ricerca per lo Studio delle Malattie Metaboliche Ossee e dell'Osteoporosi, Dipartimento di Scienze Biomediche e Biotecnologie, \\ Università degli Studi di Brescia, Viale Europa 11, Brescia, 25123 Italy
}

\section{ABSTRACT}

The aim of this review was to focus on the complex relationships between milk and dairy products intake and bone health, with particular emphasis on osteoporosis. The literature was extensively examined to provide an objective overview of the most significant achievements on the subject. Osteoporosis can be defined as a disease characterized by low bone mass and microarchitectural deterioration of bone tissue, leading to enhanced bone fragility and a consequent increase in fracture risk. Although the major determinants of peak bone mass and strength are genetic, major factors during childhood and adolescence may affect the ability to achieve peak bone mass. These include nutrition, particularly calcium and protein intake, physical activity, endocrine status, as well as exposure to a wide variety of risk factors. The role of calcium intake in determining bone mineral mass is well recognized to be the most critical nutritional factor to achieve optimal peak bone mass. The greatest amount of dietary calcium is obtained from milk and dairy foods, which also provide the human diet with vitamin $\mathrm{D}$ (particularly for products fortified with vitamin D), potassium, and other macroand micronutrients. Although studies supporting the beneficial effects of milk or calcium on bone health are predominant in the literature, perplexity or discordance on this subject was expressed by some authors. Discordant data, mainly on the risk of fractures, provided limited proof of the unfavorable effect of dairy intake. More often, discordant works indicate no effect of dairy consumption on bone safety. Some considerations can be drawn from this viewpoint. Milk and dairy products are an optimal source of calcium as well as of other limiting nutrients (e.g., potassium and magnesium),

Received May 27, 2011.

Accepted August 4, 2011

${ }^{1}$ The paper was drawn up within the Work Commission "Quality of foods from animal origin and human health" of the Italian Animal Science and Production Association.

${ }^{2}$ Corresponding author: caroli@med.unibs.it with important effects on bone health. Bioactive components occurring in milk and dairy products may play an essential role on bone metabolism, as shown by in vivo and in vitro studies on colostrum acidic proteins and milk basic proteins. Calcium intake positively affects bone mass and is crucial in childhood and youth for correct bone development. In elderly people, calcium intake as well as vitamin D availability should be carefully checked. As a general conclusion, calcium is essential for bone health, although it will not prevent bone loss due to other factors; in this context, milk and dairy foods are bioavailable, relatively inexpensive sources of calcium for the human diet.

Key words: dairy intake, bone health, calcium, osteoporosis

\section{INTRODUCTION}

Milk has served mankind for over 10,000 yr (BishopMacDonald, 2005). The origin of cheesemaking is lost in unrecorded history. Evidence exists to suggest that cheese was made as far as 7,000 BCE (O'Connor, 1993). Milk from domestic cows has been an important food source for over 8,000 yr in lactose-tolerant human societies exploiting dairy breeds, which led to a geneculture coevolution between domestic cattle and human culture (Beja-Pereira et al., 2003).

Milk has been differentially used for the production of a large variety of dairy products. As a result of the many combinations of milk, cultures, enzymes, molds, and technical processes, hundreds of varieties of dairy products are made throughout the world. Most advanced milk-processing technologies have turned it into a drink available in different forms (raw, pasteurized, ultra-high temperature, whole or skim milk, lactosefree or lactose-reduced milk, among others) compatible with special diets and specific intolerances. Wide dairy product variability occurs, as exemplified by the Italian tradition resulting in 37 Protected Designation of Origin and several local cheeses. Yogurt and fermented milk are also available in a wide range of characteristics, flavors, and sizes (IDF, 2011). 
The often recurrent debate on the effects of dairy consumption on human health must be placed in this broader context, without forgetting either the high variability of dairy foods produced by mankind over the centuries and available for today's people, or the economic and social aspects associated with milk production.

The aim of this review was to focus on the complex relationships between milk and dairy products intake and bone health, with particular emphasis on osteoporosis. The literature was extensively examined to provide an objective overview of the most significant achievements on the subject.

\section{OSTEOPOROSIS}

Osteoporosis can be defined as a disease characterized by low bone mass and microarchitectural deterioration of bone tissue, leading to enhanced bone fragility and a consequent increase in fracture risk (Consensus Development Conference, 1993). This disorder and its consequential fracture are among the leading causes of morbidity in industrialized countries (Johnell and Kanis, 2004, 2005). The number of osteoporotic fractures is likely to rise further as life expectancy increases, possibly also due to industrialization and the decrease in physical activity.

Several factors may contribute to decreasing bone mass and increasing bone fragility: among them, failure to achieve optimal peak bone mass, bone loss due to augmented resorption, and inadequate replacement of lost bone as a result of decreased bone formation (Raisz, 2005).

Although the major determinants of peak bone mass and strength are genetic, major factors during childhood and adolescence may affect the ability to achieve peak bone mass. These include nutrition, particularly calcium and protein intake, physical activity, endocrine status (such as sex hormones, vitamin D, growth hormone and IGF-1), as well as exposure to risk factors such as cigarette smoking, excessive alcohol intake, and a wide variety of intercurrent illnesses. The role of calcium intake in determining bone mineral mass is well recognized (Heaney, 2000b; Rizzoli et al., 2010).

\section{CALCIUM AND VITAMIN D}

Calcium is the major extracellular divalent cation and is essential for many important functions, including neurotransmitter release, neuronal excitability, muscle contraction, and blood coagulation. Regulation of extracellular calcium concentration is under tight endocrine control, which affects the intestinal entry and exit of calcium through the kidneys, using the large skeleton reservoir as a buffer, when necessary (Bringhurst et al., 2008).

An adequate calcium intake during growth has long been recognized to be the most critical nutritional factor for achieving optimal peak bone mass (Anderson et al., 1993; Sowers and Galuska, 1993). The 2011 report on dietary reference intakes for calcium from the Institute of Medicine, recently published in the Journal of Clinical Endocrinology \& Metabolism (Ross et al., 2011), determined the population needs for this nutrient in North America. Recommended dietary allowances (RDA), covering requirements of $>97.5 \%$ of the population for calcium, range from 700 to 1,300 $\mathrm{mg} / \mathrm{d}$ (see Table 1). According to the European Union, the RDA for calcium is $800 \mathrm{mg} / \mathrm{d}$ (Commission of the European Union, 2008). An increasing consensus exists to increase the calcium RDA; the new figures should be released within this or the next year.

The mean calcium intake in people from the United States ranged from 1,008 to $1,296 \mathrm{mg} / \mathrm{d}$ in males and from 918 to 1,186 mg/d in females; intake for girls was the lowest (918 mg/d; Bailey et al., 2010). Among European girls, the mean calcium intake varied between $600 \mathrm{mg} / \mathrm{d}$ in Italy and 1,250 mg/d in Finland (Kardinaal et al., 1999). The intake of calcium in adult women was in a similar range. After age 50, the median daily calcium intake declined (Gennari, 2001).

In a recent paper by Mangano et al. (2011), calcium intake was assessed in 9,475 American adults. The results showed that although supplemental calcium use and calcium density in the diet were highest in older age groups, they were not sufficient in meeting recommended levels. Similarly, the mean dietary calcium intake in a large population of French women was well below that recommended in current national guidelines, notably in those most at risk for fractures, such as women with a diagnosis of osteoporosis or in those in the older age groups (Fardellone et al., 2010).

Calcium enters the body only through the intestine with 2 different mechanisms: an active, vitamin Ddependent transport across the proximal duodenum and a facilitated diffusion taking place throughout the small intestine. Intestinal calcium absorption efficiency is inversely related to calcium intake, so that a diet low in calcium leads to a compensatory increase in fractional absorption, due, in part, to activation of vitamin D. This response decreases substantially with age.

Adequate levels of vitamin $\mathrm{D}$ are a prerequisite for calcium absorption. It is difficult to define adequate vitamin D nutrition because circulating vitamin $\mathrm{D}$ is derived from both dietary sources and sunlight-mediated endogenous production. Vitamin D from the diet or sun is converted in the liver to 25-hydroxy vitamin D 
Table 1. Calcium and vitamin D recommended dietary allowances (RDA) by life stage ${ }^{1}$

\begin{tabular}{|c|c|c|}
\hline Life stage $^{2}$ & $\begin{array}{c}\text { RDA of } \\
\text { calcium }^{3}(\mathrm{mg} / \mathrm{d})\end{array}$ & $\begin{array}{c}\text { RDA of } \\
\operatorname{vitamin~} \mathrm{D}^{3}(\mathrm{IU} / \mathrm{d})\end{array}$ \\
\hline \multicolumn{3}{|c|}{ Life-stage group (age and gender) } \\
\hline $1-3 \mathrm{yr}(\mathrm{M}+\mathrm{F})$ & 700 & 600 \\
\hline $4-8$ yr $(M+F)$ & 1,000 & 600 \\
\hline $9-13$ yr $(\mathrm{M}+\mathrm{F})$ & 1,300 & 600 \\
\hline $14-18$ yr $(M+F)$ & 1,300 & 600 \\
\hline $19-30 \mathrm{yr}(\mathrm{M}+\mathrm{F})$ & 1.000 & 600 \\
\hline $31-50$ yr $(\mathrm{M}+\mathrm{F})$ & 1,000 & 600 \\
\hline $51-70$ yr (M) & 1,000 & 600 \\
\hline $51-70$ yr $(\mathrm{F})$ & 1,200 & 600 \\
\hline $71+\operatorname{yr}(\mathrm{M}+\mathrm{F})$ & 1,200 & 800 \\
\hline \multicolumn{3}{|c|}{ Pregnant or lactating $(\mathrm{F})$} \\
\hline $14-18$ yr & 1,300 & 600 \\
\hline $19-50 \mathrm{yr}$ & 1,000 & 600 \\
\hline \multicolumn{3}{|l|}{ Infants } \\
\hline $0-6 \mathrm{mo}(\mathrm{M}+\mathrm{F})$ & $200^{4}$ & $400^{4}$ \\
\hline $6-12 \mathrm{mo}(\mathrm{M}+\mathrm{F})$ & $260^{4}$ & $400^{4}$ \\
\hline
\end{tabular}

$[\mathbf{2 5}(\mathbf{O H}) \mathbf{D}]$ and then in the kidney to 1,25-dihydroxy vitamin $\mathrm{D}\left[1,25(\mathrm{OH})_{2} \mathrm{D}_{3}\right]$, the active form of this vitamin.

Few foods naturally contain vitamin D, including oily fish such as salmon, mackerel, and herring, and oils from fish, including cod liver oil. In the United States, milk, some juice products, some breads, yogurts, and cheeses are fortified with vitamin D. This process was recently started also in Europe.

The Fourteenth Vitamin D Workshop (Brugge, Belgium) consensus on vitamin $\mathrm{D}$ nutritional guidelines established that an absolute minimum 25(OH)D level of $20 \mathrm{ng} / \mathrm{mL}$ is necessary in all individuals to support and maintain all of the classic actions of vitamin D on bone and mineral health. Less consensus exists on the proposal that plasma levels $<30 \mathrm{ng} / \mathrm{mL}$ would indicate a vitamin D deficiency (Holick, 2007). The large number of people of any age in the world that are frankly vitamin $\mathrm{D}$ deficient or insufficient is a risk for several poor health outcomes and they need vitamin D supplementation (Lanham-New, 2008; Henry et al., 2010).

A recent study (Melhus et al., 2010) presents data on the association between serum $25(\mathrm{OH}) \mathrm{D}$ and the incidence of hip fractures in elderly Swedish men, showing that the hazard ratio for hip fractures in subjects with serum $25(\mathrm{OH}) \mathrm{D}$ below $16 \mathrm{ng} / \mathrm{mL}$ was significantly increased to 1.71. Interestingly enough, this study showed a low incidence of vitamin D deficiency, most probably due to fortification of food and higher vitamin D intake in the Swedish population. In other parts of Europe, a higher prevalence of serum 25(OH)D below $20 \mathrm{ng} / \mathrm{mL}$ exists, which reaches a level of $23 \%$ of men in North
America. Other recent studies provide similar results (Priemel et al., 2010).

The dietary requirements for vitamin $\mathrm{D}$ at different ages, as defined by the 2011 report of Ross et al. (2011) are shown in Table 1. Recommended dietary allowances of $600 \mathrm{IU} / \mathrm{d}$ for ages 1 to $70 \mathrm{yr}$ and $800 \mathrm{IU} / \mathrm{d}$ for ages $71 \mathrm{yr}$ and older, corresponding to a serum $25(\mathrm{OH}) \mathrm{D}$ level of at least $20 \mathrm{ng} / \mathrm{mL}$, meet the requirements of at least $97.5 \%$ of the US population. According to the European Union (Commission of the European Union, 2008), the RDA for vitamin D is $5 \mu \mathrm{g} / \mathrm{d}$, corresponding to $200 \mathrm{IU}$.

\section{CALCIUM SOURCES AND BIOAVAILABILITY}

Major calcium food sources include dairy products, selected low-oxalate vegetables, legumes, nuts, and fortified foods. The greatest amount of dietary calcium is obtained from milk and dairy foods. Although there is no question of the nutritional effectiveness of the calcium provided by dairy products, some debate still exists as to whether this source of calcium is biologically better than other sources, such as calcium salts, certain vegetables, or mineral waters.

Gueguen and Pontillart (2000) reviewed the literature comparing the bioavailability of calcium in different foods. In humans, the calcium in milk and several milk derivatives (yogurts, cheeses, chocolate) is not more efficiently used than calcium salts (carbonate, gluconolactate, citramalate, lactate, acetate, and citrate) but is much better absorbed than the calcium in spinach or water cress, as these plants have high oxalate content, 
inhibiting intestinal absorption of calcium (Weaver et al., 1987; Heaney et al., 1988).

Studies in rats show that calcium in whey is as efficiently absorbed and utilized for bone mineralization as that bound to CN. Moreover, little difference occurs among the different dairy products (milk, cheese, and yogurt) in terms of calcium bioavailability. As in humans, most trials in rats have found no difference between the use of calcium from yogurt or from other dairy foods or mineral sources (Buchowski et al., 1989). Calcium from plants (apart that from crucifers), and specifically calcium from cereals, is generally less well absorbed than calcium from milk (Weaver and Plawecki, 1994).

Several studies have shown that lactose has a positive effect on calcium utilization (Favus and Angeid-Backman, 1984; Kaune, 1996), but some evidence exists that it can decrease absorption in lactase-deficient patients (Cochet et al., 1983).

\section{ADVANTAGES OF THE CALCIUM IN DAIRY PRODUCTS}

Milk and dairy products contribute many nutrients, such as calcium, vitamin D (particularly for products fortified with vitamin D), and potassium, to the diet. In the United States, the majority of fluid milk intake comes from reduced-fat (2\%) or whole (full-fat) milk, with smaller amounts consumed as fat-free (skim) or low-fat (1\%) milk (USDA and US Department of Health and Human Services, 2010). Almost half of the milk and dairy product intake in the United States comes from cheese, a limited part of which is consumed in a low-fat form. Choosing fat-free or low-fat milk and milk products provides the same calcium with less solid fat and, thus, fewer calories. In addition, selecting more milk-group intake as fat-free or low-fat fluid milk or yogurt rather than as cheese can increase the intake of potassium, vitamin $\mathrm{A}$, and vitamin $\mathrm{D}$, and decrease intake of sodium, cholesterol, and saturated fatty acids.

As for the European Union, fresh milk (drinking milk, yogurt, and desserts) accounts for the $31.6 \%$ of the whole dairy products, whereas $37.3 \%$ of milk is used for cheeses, $16.2 \%$ for butter, $5 \%$ for other products, $4.7 \%$ for whole milk powder, $3.8 \%$ for skim milk powder, and $1.4 \%$ for CN (European Commission, 2006). Thus, almost $40 \%$ of EU milk is consumed as cheese, with 4 Member States (Germany, France, Italy, and the Netherlands) producing more than $75 \%$ of EU cheese (European Commission, 2006). Large differences occur among the Member States in the consumption of milk and dairy products (European Commission, 1999).

As an example of a European country, data on mean daily consumption of milk and dairy products from an Italian national survey are shown in Table 2 (Leclercq et al., 2009), whereas calcium and vitamin D intakes resulting from the same survey are reported in Table 3 (Sette et al., 2010). The higher density in calcium in female adults with respect to male adults may be in part attributed to a higher proportion of their diet represented by "milk, milk products, and substitutes" (10\% in weight of diet in females vs. $9 \%$ in males; Sette et al., 2010).

It is especially important to establish the habit of drinking milk in young children, as those who consume milk at an early age are more likely to do so as adults. For individuals who are lactose intolerant, low-lactose and lactose-free milk products are available. The Dietary Guidelines for Americans 2010 (USDA and US Department of Health and Human Services, 2010) suggest that people not consuming dairy products should consume foods that provide the range of nutrients generally obtained from the milk group, including protein, calcium, potassium, magnesium, vitamin $\mathrm{D}$, and

Table 2. Mean daily consumption $(\mathrm{g} / \mathrm{d})$ of milk and dairy products: Italian National Food Consumption Survey INRAN-SCAI 2005-2006

\begin{tabular}{|c|c|c|c|c|c|}
\hline Life-stage group ${ }^{2}$ & Milk $^{3}$ & Yogurt $^{4}$ & Cheese $^{5}$ & Desserts $^{6}$ & Total \\
\hline Whole population $(\mathrm{n}=3,323)$ & 119.3 & 20.6 & 57.0 & 1.1 & 198 \\
\hline Infants $0-2.9$ yr $(\mathrm{M}+\mathrm{F} ; \mathrm{n}=52)$ & 334 & 37.3 & 24.4 & 1.5 & 397.3 \\
\hline Children 3-9.9 yr $(\mathrm{M}+\mathrm{F} ; \mathrm{n}=193)$ & 197.2 & 16.7 & 44.3 & 0.9 & 259.1 \\
\hline Teenagers $10-17.9$ yr $(\mathrm{M} ; \mathrm{n}=108)$ & 168.3 & 13.5 & 63.8 & 0.5 & 246.0 \\
\hline Teenagers $10-17.9$ yr $(\mathrm{F} ; \mathrm{n}=139)$ & 139.8 & 20.8 & 54.6 & 0.5 & 215.7 \\
\hline Adults $18-64.9$ yr $(\mathrm{M} ; \mathrm{n}=1,068)$ & 94.3 & 16.3 & 95.6 & 1.2 & 177.5 \\
\hline Adults $18-64.9$ yr $(\mathrm{F} ; \mathrm{n}=1,245)$ & 110.5 & 26.8 & 54.5 & 1.1 & 192.9 \\
\hline Elderly $\geq 65$ yr $(M ; n=202)$ & 119.7 & 10.6 & 57.0 & 0.7 & 188.0 \\
\hline Elderly $\geq 65$ yr $(\mathrm{F} ; \mathrm{n}=316)$ & 129.9 & 18.9 & 49.9 & 0.9 & 199.6 \\
\hline \multicolumn{6}{|l|}{${ }^{1}$ Source: Leclercq et al. (2009). } \\
\hline \multicolumn{6}{|l|}{${ }^{2} \mathrm{M}=$ male; $\mathrm{F}=$ female. } \\
\hline \multicolumn{6}{|c|}{${ }^{3}$ Milk, milk-based beverages, human milk, infant formula, and substitute. } \\
\hline \multicolumn{6}{|c|}{${ }^{4}$ Yogurt and fermented milk. } \\
\hline \multicolumn{6}{|l|}{${ }^{5}$ Cheese and substitutes. } \\
\hline
\end{tabular}


Table 3. Calcium and vitamin D daily intakes by life stage and sex from the Italian National Food Consumption Survey INRAN-SCAI 2005-2006 ${ }^{1}$

\begin{tabular}{|c|c|c|c|c|}
\hline \multirow[b]{2}{*}{ Life-stage group ${ }^{2}$} & \multicolumn{2}{|c|}{ Calcium intake $(\mathrm{mg} / \mathrm{d})$} & \multicolumn{2}{|c|}{ Vitamin D intake $(\mu \mathrm{g} / \mathrm{d}$} \\
\hline & Mean & Median & Mean & Median \\
\hline Infants $0-2.9$ yr $(\mathrm{M}+\mathrm{F} ; \mathrm{n}=52)$ & 664 & 669 & 1.8 & 1.1 \\
\hline Children 3-9.9 yr $(\mathrm{M}+\mathrm{F} ; \mathrm{n}=193)$ & 749 & 714 & 2.0 & 1.6 \\
\hline Teenagers $10-17.9$ yr $(\mathrm{M} ; \mathrm{n}=108)$ & 892 & 848 & 2.6 & 1.9 \\
\hline Teenagers $10-17.9$ yr $(\mathrm{F} ; \mathrm{n}=139)$ & 770 & 759 & 2.4 & 1.9 \\
\hline Adults $18-64.9$ yr $(\mathrm{M} ; \mathrm{n}=1,068)$ & 799 & 756 & 2.6 & 1.9 \\
\hline Adults $18-64.9$ yr $(\mathrm{F} ; \mathrm{n}=1,245)$ & 730 & 697 & 2.3 & 1.5 \\
\hline Elderly $\geq 65$ yr $(\mathrm{M} ; \mathrm{n}=202)$ & 825 & 778 & 2.5 & 1.9 \\
\hline Elderly $>65$ yr $(\mathrm{F} ; \mathrm{n}=316)$ & 754 & 735 & 1.8 & 1.4 \\
\hline
\end{tabular}

${ }^{1}$ Source: Sette et al. (2010)

${ }^{2} \mathrm{M}=$ male; $\mathrm{F}=$ female

vitamin A, soy beverages fortified with calcium and vitamins $\mathrm{A}$ and $\mathrm{D}$ being considered part of the milk and milk products because of their similarity to milk both nutritionally and in their use in meals.

Milk calcium content is $1.2 \mathrm{~g} / \mathrm{kg} ; 20 \%$ is bound to CN and the remainder, highly available, is in mineral form. Calcium content in dairy products ranges from $0.6 \mathrm{~g} / \mathrm{kg}$ (cottage cheese) to $7.3 \mathrm{~g} / \mathrm{kg}$ (Cheddar cheese) as shown in Table 4 (Pennington, 1994). Cream, sour cream, and cream cheese are not included due to their low calcium content (USDA and US Department of Health and Human Services, 2010). Among Italian Protected Designation of Origin cheeses, calcium content ranged from 71.4 to $9.75 \mathrm{~g} / \mathrm{kg}$ in different hard and semi-hard products, reaching 11.6 and $13.3 \mathrm{~g} / \mathrm{kg}$, for Parmigiano Reggiano and Grana Padano respectively (Manzi et al., 2007).

Under normal diet conditions, about $40 \%$ of milk and cheese calcium is absorbed. As already pointed out, no difference exists in availability of calcium from dairy foods or from commonly used dietary supplements whose coefficient of absorption is about 30 to $40 \%$, with the exception of calcium malate, which can offer a better bioavailability.

Different from calcium supplements, dairy products provide simultaneous intake of phosphorus, essential for bone deposition (Heaney, 1996). Dairy products do not contain substances inhibiting intestinal absorption of calcium, like phytates, oxalates, or the polyphenols of certain vegetables and also may be absorbed in the absence of vitamin D under the influence of lactose in the distal small intestine via the paracellular route (Guéguen and Pointillart, 2000). Milk calcium absorption is limited by achlorhydria, as in this condition, calcium bound to proteins remains in solution.

\section{BENEFICIAL EFFECTS OF MILK OR CALCIUM ON BONE HEALTH}

Different reviews and viewpoints are already available supporting beneficial effects of milk or calcium on bone health. An adequate calcium intake increases bone mineral density during skeletal growth and prevents bone loss and osteoporotic fractures in the elderly (Lindsay and Nieves, 1994; Murray, 1996; Heaney, 2000b; Huth et al., 2006; Straub, 2007; Rizzoli et al., 2010). According to Francis et al. (2006), the adult population should be encouraged to a dietary calcium intake higher than 700 $\mathrm{mg} / \mathrm{d}$. Moreover, individuals at risk or with established osteoporosis should consider increasing their dietary calcium intake to 1,000 to $1,500 \mathrm{mg} / \mathrm{d}$. Calcium supplements appear to be effective in decreasing bone loss in women late post menopause ( $>5 \mathrm{yr}$ ), particularly in those with low habitual calcium intake $(<400 \mathrm{mg} / \mathrm{d}$; Lanham-New, 2008).

Bischoff-Ferrari and Staehelin (2008) reviewed the potential of vitamin for the prevention of falls and fractures at older ages. The review concludes that vitamin

Table 4. Nutrient content per $100 \mathrm{~g}$ of various dairy foods ${ }^{1}$

\begin{tabular}{lcccc}
\hline Dairy food & $\begin{array}{c}\text { Calcium } \\
(\mathrm{mg})\end{array}$ & $\begin{array}{c}\text { Potassium } \\
(\mathrm{mg})\end{array}$ & $\begin{array}{c}\text { Protein } \\
(\mathrm{g})\end{array}$ & $\begin{array}{c}\text { Sodium } \\
(\mathrm{mg})\end{array}$ \\
\hline Milk, skim & 123 & 166 & 3 & 51 \\
Yogurt, nonfat & 199 & 255 & 6 & 77 \\
Cheddar cheese & 729 & 100 & 25 & 629 \\
American cheese & 443 & 164 & 21 & 1,450 \\
Cottage cheese & 61 & 81 & 12 & 406 \\
\hline
\end{tabular}

${ }^{1}$ Modified from Weinsier and Krumdieck (2000, which used data from Pennington, 1994). 
D should be provided to everybody, starting at age 60 for optimal bone and muscle health.

According to all of the above-mentioned authors, dairy products may be an optimal source of calcium at all ages as milk provides both calcium and proteins. Assuming high calcium-containing foods allow meeting calcium daily dietary requirements, dairy products may represent the best sources of it due to their high content, high absorptive rate, and relatively low cost (Sunyecz, 2008).

In this context, Weaver (2008) found that dietary calcium predicts 10 to $15 \%$ of skeletal calcium retention during adolescence. Along this way, Heaney (2009) pointed out the difficulty to devise a bone healthy diet without including 3 servings of dairy food per day, because dairy products provide more protein, calcium, magnesium, potassium, zinc, and phosphorus per calorie than any other typical food found in the adult diet (Heaney, 2000a; USDA, 2005). Dairy foods are excellent sources for these nutrients, and diets low in dairy will almost always be low in one or more of the nutrients necessary for bone health (Heaney, 2009).

Milk is the most economical source of many limiting nutrients, especially calcium, potassium, and magnesium. Overall evidence suggests that being a lactovegetarian implies greater health benefits and decreased health risks than being a vegan (Weaver, 2009). In a prospective cohort study of self-reported fracture risk at follow-up, Appleby et al. (2007) showed that the risk was similar for meat or fish eaters and vegetarians but was higher in vegans. The higher risk among vegans was supposed to be the consequence of their considerably lower mean calcium intake. The authors suggest that vegans, who do not consume dairy products, should ensure an adequate calcium intake from other sources such as almonds, sesame seeds, and calcium-fortified drinks.

Tucker (2009) supported encouragement to follow a balanced diet with plenty of fruit and vegetables, adequate dairy and other protein-rich foods, and preference to foods with low nutrient density. She observed that calcium in foods such as milk is an excellent option because it is packaged in a natural complex carrying other important nutrients.

An adequate calcium, vitamin $\mathrm{D}$, and protein intake results in decreased bone remodeling, better calcium retention, and decreased age-related bone loss and fracture risk, as pointed out by Peters and Martini (2010). According to this review, a healthy dietary pattern including dairy products, fruits and vegetables, and adequate amounts of meat, fish, and poultry is positively related to bone health. Moreover, mineral and vitamin supplementation should be monitored by health profes- sionals, as it could have adverse effects and be insufficient to ensure optimal protection of bone health.

A claim of calcium and maintenance of normal bone and teeth has been assessed by the European Food Safety Authority with a favorable outcome (EFSA, 2009).

\section{BENEFITS FROM MILK: SOME EXPERIMENTAL DETAILS}

Some of the numerous original articles referring to positive effects of calcium or milk intake on bone health will be summarized to give an overview of the different research approaches trying to establish and quantify the effects of dairy and calcium intake on bone health at different ages and in different physiological and environmental conditions.

Significant associations between milk intake during adulthood and bone mineral density (BMD) of the axial and appendicular skeleton were found in the study of Soroko et al. (1994), including 581 postmenopausal white women (average age $=70.6 \mathrm{yr}$ ). The relationship, independent of other major BMD determinants, was strongest for milk intake during midlife (20 to $50 \mathrm{yr}$ of age) supporting the notion that a calcium-rich diet helps to minimize bone loss.

Nguyen et al. (2000) carried out a cross-sectional epidemiological study involving 1,075 women and 690 men (average age: $69 \mathrm{yr}$ ). These data suggest a positive and interactive association of BMD with body mass index (BMI), quadriceps strength, and dietary calcium intake, which could potentially translate into practical strategies for the prevention of osteoporosis in the elderly. A significant correlation between forearm BMD and milk consumption was also found by Hawker et al. (2002) in young adult Norwegian women.

The advantages of dairy consumption to bone health are strongest during growth. A retrospective study by Kalkwarf et al. (2003) investigated the effects of milk intake during childhood and adolescence on adult bone density and osteoporotic fractures in 3,251 non-Hispanic US white postmenopausal women. A lower bone mass in adulthood was found in women with low milk intake during childhood (ages 5-12 yr) and adolescence (ages 13-17 yr). Low milk intake during childhood was associated with $11 \%$ of osteoporotic fractures in women later in life. These compelling results were highlighted by Tucker (2003).

During the transition to young adulthood, mean daily calcium intake of North American females and males was found to decrease by an average of 153 and 194 mg, respectively (Larson et al., 2009). This study suggested interventions targeted to adolescents to address 
the availability of milk at meals and other supports for healthful eating.

A population of 755 males (mean age $=18.7 \mathrm{yr}$ ) entering the United States Military Academy was examined by Ruffing et al. (2006). A questionnaire assessed exercise frequency, milk, caffeine, alcohol consumption, and tobacco use in relation to BMD. The results confirmed the importance of race to determine bone size and BMD. African-Americans had significantly higher hip, spine, and heel BMD and greater tibial mineral content and cortical thickness than Caucasians and Asians. Exercise levels and milk intake were positively related to bone density and size with an apparent interaction between the 2 parameters.

A cross-sectional, retrospective, observational study was performed in 1,771 healthy, early postmenopausal women in Northern Italy by Varenna et al. (2007). Calcium intake was not associated with osteoporosis when overweight was not considered. However, when overweight was considered, women with the lowest calcium intake were more likely to have osteoporosis than women with the highest calcium intake. The authors suggest that a relatively simple dietary modification at population level, promoting calcium intake, could play an important role in decreasing morbidity and mortality in postmenopausal women.

Inhibition of bone turnover by milk intake in postmenopausal women was demonstrated by Bonjour et al. (2008). Thirty healthy postmenopausal women (average age $59.3 \mathrm{yr}$ ) received either $500 \mathrm{~mL}$ of semi-skim milk, thus providing a total of $1,200 \mathrm{mg}$ of calcium, or no milk supplement. A 6-wk period of milk supplementation induced a decrease in several biochemical variables compatible with diminished bone turnover mediated by decrease in parathyroid hormone.

This effect is comparable to that of calcium and vitamin D supplementation as recently shown also by Kärkkäinen et al. (2010) who measured BMD in women aged 65 to 71 yr by a randomized population-based open trial. Daily vitamin D and calcium supplementation had a positive effect on the skeleton in ambulatory postmenopausal women.

It appears, therefore, that a nutritional approach to postmenopausal alteration in bone metabolism might be a valuable measure in the primary prevention of osteoporosis.

Nicklas et al. (2009) recommend 3 to 4 servings from the dairy group of foods to all people older than $9 \mathrm{yr}$ of age as a way to ensure adequate intake of calcium and magnesium.

Lumbar bone mineral content (BMC) and BMD were found to be tightly associated with milk consumption, but not with other calcium sources (Esterle et al., 2009). Girls with milk intakes below $55 \mathrm{~mL} / \mathrm{d}$ have significantly lower BMD and BMC compared with girls consuming over $260 \mathrm{~mL} / \mathrm{d}$.

Bioactive components from milk may directly affect bone health. Milk whey protein, especially the fraction with alkaline isoelectric point (milk basic protein, MBP), suppressed bone resorption and prevented bone loss caused by ovariectomy in aged rats (Toba et al., 2000). Supplementation with MBP also increased bone mineral density and suppressed urine levels of bone resorption biomarkers in young women (Aoe et al., 2001; Yamamura et al., 2002; Itabashi, 2006; Uenishi et al., 2007), in menopausal women (Aoe et al., 2005) and in healthy older women (>65 yr; Aoyagi et al., 2010). In particular, MBP directly suppressed osteoclast-mediated bone resorption and led to decreased osteoclast number in animal studies (discussed in Uenishi et al., 2007). In a recent paper, Morita et al. (2011) identified lactoperoxidase as the predominant inhibitor of osteoclastogenesis in MBP.

Bovine colostrum acidic proteins $(2-50 \mathrm{mg} / \mathrm{d})$ was able to prevent osteoporosis in ovariectomized rats ( Du et al., 2011b), an effect likely related to the content in bovine colostrum acidic proteins of several substances stimulating bone mineralization and growth (osteopontin, epidermal growth factor, and IGF-2). Consistently, skim milk powder had no effect on bone loss in ovariectomized rats probably due to a loss of biological protein activity consequent to processing heat treatment (Du et al., 2011a).

Among bioactive peptides, which can be derived from milk proteins, $\mathrm{CN}$ phosphopeptides (CPP) are carriers for different minerals, especially Ca (FitzGerald, 1998). Casein phosphopeptides obtained by in vitro enzymatic hydrolysis of $\mathrm{CN}$, have been shown to enhance calcium solubility (Reeves and Latour, 1958) and to increase the calcification of embryonic rat bones in their diaphyseal area (Gerber and Jost, 1986). Donida et al. (2009) reported that a $\mathrm{CN}$-derived hydrolysate containing CPP modulates calcium uptake and the differentiation pathways in human osteoblast-like cells. Tulipano et al. (2010) demonstrated that CPP may directly affect osteoblast-like cell growth, calcium uptake, and ultimately calcium deposition in the extracellular matrix, either with stimulatory or inhibitory effects.

Several aspects of the importance of calcium for bone health, in conclusion, have been clarified in the last years. Dietary calcium can augment the ability of physical activity to strengthen growing bone through allowing increased bone mineralization of larger bone sizes. Furthermore, because high calcium intake can decrease homeostatic bone remodeling, it is likely to improve skeletal strength even if it has no appreciable effect on bone mass or bone balance (Heaney and Weaver, 2005). 


\section{PERPLEXING OR DISCORDANT WORKS}

Although studies supporting beneficial effects of milk or calcium on bone health are predominant in the literature, perplexity or discordance on this subject was expressed by some authors.

In a review article, Weinsier and Krumdieck (2000) critically examined studies on dairy food intake and bone health. The authors did not develop a metaanalysis of these studies, and conclusions were based on the comparison of the number of studies with positive, negative, or inconclusive results. They noticed that among studies showing a significant outcome, the ratio of favorable versus unfavorable effects was 8.0, but among studies providing strong evidence, the ratio was only 2.0. The group of subjects accounting primarily for these favorable ratios was composed by young white women, suggesting that a beneficial effect is most likely to occur during the period of maximum bone accretion (e.g., Recker et al., 1992). On the contrary, too few studies exist in males and minority ethnic groups to determine whether dairy foods really promote bone health in most of the US population.

Subsequently, Lanou et al. (2005) looked for studies on the relationship between milk, dairy products, or calcium intake and bone mineralization or fracture risk in children and young adults (1-25 yr). Their search yielded 58 studies: 22 cross-sectional, 13 retrospective, 10 longitudinal prospective studies, and 13 randomized, controlled trials. The authors concluded that scant evidence supports nutritional guidelines specifically focused on increasing milk or other dairy product intake for promoting child and adolescent bone mineralization.

Along with this view, Álvarez-León et al. (2006), after searching the MEDLINE database from 1966 to 2005, emphasized limitations to the work published up to that moment, both in methodology and sample size; in their opinion, the published evidence provides only weak evidence of the protective capacity of dairy products on bone health, and more prospective studies should be performed in order to better understand the relationship between dairy product intake and bone health.

Even if general agreement exists in the literature on the importance of calcium and vitamin D during the periods of rapid bone growth in childhood and adolescence, the evidence regarding the utility of these supplements to prevent or delay bone loss in adults is not as compelling according to Lee and Majka (2006). The rationale of this commentary was mainly based on data obtained in 36,282 postmenopausal women enrolled in the Women's Health Initiative trial, who received $1 \mathrm{~g}$ of calcium carbonate with $400 \mathrm{IU}$ of vitamin D daily or placebo. The results of this trial showed limited benefits of calcium and vitamin D supplements on fracture prevention in a follow-up period of $7 \mathrm{yr}$ (Jackson et al., 2006).

An expert roundtable (Roux et al., 2008) concluded that, based on newly emerging data regarding calcium supplementation and increased vitamin D intake, the recommendations for calcium intake in postmenopausal women may be unnecessarily high. In the opinion of Lanou (2009), all nutrients found in dairy foods are readily available in healthier foods from plant sources. According to this author, bones are better served by paying attention to calcium balance and focusing on the need to increase fruit and vegetable intakes, limiting animal protein, exercising regularly, getting adequate sunlight exposure or supplemental vitamin D, and getting approximately $500 \mathrm{mg} \mathrm{Ca} / \mathrm{d}$ from plant sources. Therefore, dairy products should not be recommended in a healthy vegetarian diet. This was the counterpart to the point article by Weaver (2009).

However, a meta-analysis of 9 studies of 2,749 subjects comparing BMD of vegans, lacto-ovo-vegetarians, and omnivores concluded that, compared with omnivores, vegans had 6\% lower BMD and lacto-ovo-vegetarians had $2 \%$ lower BMD at the lower lumbar spine; the effect size was similar at the femoral neck (Ho-Pham et al., 2009). According to this study, the magnitudes of the differences were clinically insignificant. Nonetheless, most subjects $(\mathrm{n}=1,865)$ derived from one paper (Wang et al., 2008) that considered together a very wide range of ages (from 20 to $89 \mathrm{yr}$ ).

Lekamwasam et al. (2009) found a 5.8\% prevalence of osteoporosis in 1,174 male volunteers aged $50 \mathrm{yr}$ or more in Sri Lanka. The study showed that phalangeal BMD of the volunteers was not associated with smoking or alcohol habits or to milk consumption. On the contrary, advancing age, less physical activity, and low BW were associated with low BMD.

\section{CALCIUM INTAKE AND FRACTURE RISK}

What has been reported so far underlines the difficulty of performing studies demonstrating the efficacy of a calcium-rich diet on bone health. Many parameters need to be considered: genetic hereditariness; individual habits of exposure to sunlight, inducing vitamin D synthesis; and differences in life style that affect bone making, such as physical exercise. Last, it also is important to consider the assumption in the diet of substances known to interact negatively with calcium absorption or excretion. For instance, chronic metabolic acidosis, consequent of a high-protein diet, was proposed by some authors as a risk factor for osteoporosis or bone fractures due to the increase in urinary calcium excretion resulting from the metabolic acidity of protein 
metabolism (Barzel and Massey, 1998; Bushinsky, 2001; Arnett, 2008). However, this effect on promoting bone mineral loss was negated by others (Bonjour, 2005; Cao et al., 2011; Thorpe and Evans, 2011).

All the relevant factors conditioning bone health need to be considered instead of focusing the attention only on one aspect at a time. These factors appear even most important when the relationship between calcium intake and risk of bone fractures, particularly hip fractures, is considered. Hip fractures are obviously an important public health problem but prevention remains problematic because only few of the established risk factors are easily amenable to change. These risk factors are old age, female sex, white race, low weight, physical inactivity, psychotropic medications and, in women, estrogen deficiency (Cumming and Klineberg, 1994). Other possible risk factors for hip fractures include alcohol, caffeine, and smoking (WHO/FAO, 2003).

A case $(n=209)$-control $(n=207)$ study of hip fracture risk in the elderly was carried out in Australia by Cumming and Klineberg (1994). Self-reported consumption of milk and dairy products, particularly at the age of $20 \mathrm{yr}$, was associated with an increased risk of hip fracture in old age. The authors themselves conclude that these surprising findings could be due to chance or bias, mainly derived from the use of subject recall to measure exposure that occurred many decades in the past.

Feskanich et al. (1997) focused their investigation on dietary sources of calcium to assess the validity of advising women to increase their milk consumption for the prevention of osteoporosis. The results, most directly applicable to middle-aged white women in the United States, suggest that although therapeutic levels of calcium supplementation may protect against osteoporotic fractures at particular bone sites, protective effects against hip or forearm fractures is unlikely to come from high consumption of milk or other food sources of calcium during midlife. This 12-yr analysis was expanded in an 18-yr prospective analysis carried out on 72,337 postmenopausal women (Feskanich et al., 2003). Dietary intake and nutritional supplement use were assessed at baseline in 1980 and updated several times during follow-up. A total of 603 incident hip fractures resulting from low or moderate trauma were identified. Neither total calcium intake nor milk consumption was associated with hip fracture risk. An adequate vitamin $\mathrm{D}$ intake was associated with a lower risk of osteoporotic hip fractures in these postmenopausal women.

Kanis et al. (2005) carried out a meta-analysis on milk intake and fracture risk including 39,563 men and women (69\% female) from 6 prospectively stud- ied cohorts. A low intake of calcium (less than 1 glass of milk daily) was not associated with a significantly increased risk of any fracture, osteoporotic fracture or hip fracture. According to the authors, a self-reported low intake of milk was not associated with any marked increase in fracture risk and the use of this risk indicator was of little or no value in case-finding strategies.

Calcium intake and hip fracture risk in men and women were also considered in a comprehensive meta-analysis of prospective cohort studies and randomized controlled trials not differentiating supplements from dairy food (Bischoff-Ferrari et al., 2007). Among females, the cohort data (including 170,991 women) suggest a neutral effect of calcium intake on hip fractures, but data from controlled trials of calcium supplementation (including 5,666 women) suggest an adverse effect, even among adherent subjects. In addition, controlled trial data for any non-vertebral fractures indicate a neutral effect of calcium with respect to fracture reduction. Also, the few studies in males included in this meta-analysis did not support a beneficial effect of calcium intake on hip fracture risk. A meta-analysis recently published by the same authors (Bischoff-Ferrari et al., 2011) considered the effect of milk intake on hip fracture in middle-aged or older men and women. In females, the relative risk of hip fracture per glass of milk was similar, whereas data in males are once again too limited to draw conclusions.

Evaluation of calcium intake in a group of elderly patients with hip fractures showed that their mean calcium intake was above the recommended daily intake of $800 \mathrm{mg} / \mathrm{d}$ (Cho et al., 2008). However, more than onethird of these patients had a lower intake. The authors focused on the complex relationship between calcium intake and fracture susceptibility, suggesting further studies on the paradox that subjects with sufficient or high calcium intake still have a high incidence of hip fractures.

Different conclusions were reached by a meta-regression analysis carried out by Rabenda et al. (2011) on a total of 15 randomized trials $(\mathrm{n}=47,365)$ evaluating the relationship between BMD changes and decrease in risk of fractures among patients receiving calcium with or without vitamin D supplementation. The authors started from 2,051 potentially relevant articles identified and screened for retrieval. They excluded 1,966 irrelevant articles, 85 abstracts, and 67 other articles for different reasons (editorials, reviews, randomized trials using calcium in the control group, and trials with vitamin $\mathrm{D}$ only, children, and adolescent patients). The articles not reporting fracture data or BMD studies were also excluded. No evidence was found of a relationship between BMD changes and decrease of risk of fractures among patients receiving calcium with or without vitamin D supplementation. In accordance 
with Heaney and Weaver (2005), the authors suggested that high calcium and vitamin D intakes can improve skeletal strength, even if they have no appreciable effect on bone mass or bone balance.

In a very recent review evaluating the effectiveness of calcium supplementation to prevent osteoporosis-related fractures in postmenopausal women Spangler et al. (2011) emphasize the results of controlled clinical trials that indicate that calcium supplementation does not significantly decrease fracture risk in postmenopausal women. They conclude, however, from the same studies, that beneficial effects on fracture risk may be seen in women who are adherent to the therapy.

\section{FORTIFIED DAIRY PRODUCTS}

Milk is an appropriate vehicle to be fortified with calcium, vitamin D, and other minerals. Many studies were performed in the last few years on the effect of fortified dairy products on the different aspects of bone metabolism. Palacios et al. (2005) evaluated the changes in bone turnover markers after calciumenriched milk supplementation in healthy postmenopausal women. The daily intake of $750 \mathrm{~mL}$ of enriched skim milk containing $1,200 \mathrm{mg}$ of calcium appeared to be a useful, safe, and acceptable measure for calcium supplementation in healthy elderly postmenopausal women. The authors suggested the daily intake of at least 3 glasses of this calcium, phosphorus, lactose, and vitamin D fortified skim milk containing 1,200 $\mathrm{mg}$ of calcium for decreasing bone resorption in women 10 or more years past menopause.

The absorption of calcium from a range of fortified milks was measured in humans with the use of stable isotopes (López-Huertas et al., 2006), showing that calcium-enriched milks are a valuable source of wellabsorbed calcium.

The effect of a fortified milk drink on vitamin D status and bone turnover was investigated in postmenopausal women from Southeast Asia (Kruger et al., 2006). The fortified milk intervention was able to significantly improve vitamin D status, lower parathyroid hormone (PTH) levels, and decrease bone turnover in this study population.

According to Moschonis and Manios (2006) recommended intakes of vitamin D and calcium via fortified dairy products for 12 mo can induce favorable changes in the pelvis, total spine, and total body BMD in Greek postmenopausal women but not in quantitative ultrasound parameters of the calcaneus. The application of a holistic intervention approach combining nutrition, education, and consumption of fortified dairy products for 12 mo (Manios et al., 2007) or for 5 winter months (Manios et al., 2009) induced more favorable changes in biochemical indices of bone metabolism than can calcium supplementation alone.

In most trials reviewed by Cranney et al. (2007), the effects of vitamin $D$ and calcium could not be separated. Vitamin D (>700 IU/d) associated with calcium supplementation compared with placebo has a small beneficial effect on BMD, and decreases the risk of fractures and falls, although benefit may be confined to specific subgroups.

In a 2-yr randomized controlled trial, calcium- and vitamin D-fortified milk stopped or slowed bone loss at several clinically relevant skeletal sites in older men (Daly et al., 2006). Sustained benefits for BMD were observed after withdrawal of supplementation (Daly et al., 2008).

According to Bonjour et al. (2009), fortified soft plain cheese consumed by elderly women with vitamin D insufficiency can decrease bone resorption markers by positively influencing calcium and protein economy, as expressed by decreased parathyroid hormone and increased IGF-I, respectively. Such a dietary intervention might uncouple, at least transiently, bone resorption from bone formation and thereby attenuate age-related bone loss.

A high-calcium milk drink with added vitamin D, magnesium, and zinc was compared with a placebo (Kruger et al., 2010). The high-calcium milk drink significantly improved vitamin D status and decreased bone turnover in 2 groups of Southeast Asian women.

Intakes of vitamin D of about $22.5 \mu \mathrm{g} / \mathrm{d}$ and of calcium of about 1,200 mg from fortified dairy foods for 30 mo, with compliance ensured by lifestyle and nutrition education sessions, was able to induce favorable changes in arms, total spine, and total body BMD of postmenopausal women (Moschonis et al., 2010).

van der Hee et al. (2009) designed a calcium-fortified ice cream formulation, lower in fat than regular ice cream, which could provide a source of additional dietary calcium. Calcium bioavailability in the 2 calciumfortified ice cream formulations was as high as milk, indicating ice cream as a good vehicle for delivery of calcium.

\section{CONCLUSIONS}

As concluded by the Committee of the Institute of Medicine (Ross et al., 2011), available scientific evidence supports a key role of calcium and vitamin D in skeletal health, consistent with a cause-and-effect relationship and providing a sound basis for determination of intake requirements. The complexity of the relationship between dairy intake and bone health is wide, as we have shown in this short state of the art. Bone metabolism is influenced by several factors, including 
genetic, hormonal, physiologic, and nutrition effects. Many confounding elements can bias the experimental trials, in particular the retrospective ones based on selfreported data on milk and dairy intake. Fortified dairy products can also be a further confounding factor when comparing studies carried out in countries characterized by different use of these products in the population. The wide variety of dairy products is also an aspect that should be considered in evaluating the different amounts of bioavailable nutrients that can affect bone health. In any case, some general conclusions can be drawn. First, milk and dairy products are an optimal source of calcium as well as other limiting nutrients (e.g., potassium and magnesium), with important effects on bone health. Bioactive components occurring in milk and dairy products may play an essential role in bone metabolism, as shown by colostrum acidic proteins and MBP. Calcium intake positively affects bone mass and is crucial in childhood and youth for correct bone development. In elderly people, calcium intake as well as vitamin D availability should be carefully checked. The literature reporting favorable effects of milk and dairy products on bone is highly predominant compared with contradictory papers, including discordant and perplexing works. Discordant data, mainly on the risk of fractures, provided limited proof of the unfavorable effects of dairy intake. The majority of the contradictory papers indicate that dairy consumption does not alter bone safety. The best conclusion comes from Lindsay and Nieves (1994): "Calcium will not prevent the bone loss due to other factors . . nonetheless, milk is a bioavailable, relatively inexpensive source of calcium for those who can ingest it."

\section{REFERENCES}

Álvarez-León, E.-E., B. Román-Viñas, and L. Serra-Majem. 2006. Dairy products and health: A review of the epidemiological evidence. Br. J. Nutr. 96:S94-S99.

Anderson, J. J. B., F. A. Tylavsky, L. Halioua, and J. A. Metz. 1993. Determinants of peak bone mass in young adult women: A review. Osteoporos. Int. 3(Suppl. 1):32-36.

Aoe, S., T. Koyama, A. Toba, A. Itabashi, and Y. Takada. 2005. A controlled trial of the effect of milk basic protein (MBP) supplementation on bone metabolism in healthy menopausal women. Osteoporos. Int. 16:2123-2128.

Aoe, S., Y. Toba, H. Yamamura, M. Kawakami, M. Yahiro, A. Kumegawa, A. Itabashi, and Y. Takada. 2001. Controlled trial of the effects of milk basic protein (MBP) supplementation on bone metabolism in healthy adult women. Biosci. Biotechnol. Biochem. 65:913-918.

Aoyagi, Y., H. Park, S. Park, K. Yoshiuchi, H. Kikuchi, H. Kawakami, Y. Morita, A. Ono, and R. J. Shephard. 2010. Interactive effects of milk basic protein supplements and habitual physical activity on bone health in older women: A 1-year randomized controlled trial. Int. Dairy J. 20:724-730.

Appleby, P., A. Roddam, N. Allen, and T. Key. 2007. Comparative fracture risk in vegetarians and nonvegetarians in EPIC-Oxford. Eur. J. Clin. Nutr. 61:1400-1406.
Arnett, T. R. 2008. Extracellular pH regulates bone cell function. J. Nutr. 138(Suppl.):415S-418S.

Bailey, R. L., K. W. Dodd, J. A. Goldman, J. J. Gahche, J. T. Dwyer, A. J. Moshfegh, C. T. Sempos, and M. F. Picciano. 2010. Estimation of total usual calcium and vitamin D intakes in the United States. J. Nutr. 140:817-822.

Barzel, U. S., and L. K. Massey. 1998. Excess dietary protein can adversely affect bone. J. Nutr. 128:1051-1053.

Beja-Pereira, A., G. Luikart, P. R. England, D. G. Bradley, O. C. Jann, G. Bertorelle, A. T. Chamberlain, T. P. Nunes, S. Metodiev, N. Ferrand, and G. Erhardt. 2003. Gene-culture coevolution between cattle milk protein genes and human lactase genes. Nat. Genet. 35:311-313.

Bischoff-Ferrari, H. A., B. Dawson-Hughes, J. A. Baron, P. Burckhardt, R. Li, D. Spiegelman, B. Specker, J. E. Orav, J. B. Wong, H. B. Staehelin, E. O'Reilly, D. P. Kiel, and W. C. Willett. 2007. Calcium intake and hip fracture risk in men and women: A metaanalysis of prospective cohort studies and randomized controlled trials. Am. J. Clin. Nutr. 86:1780-1790.

Bischoff-Ferrari, H. A., B. Dawson-Hughes, J. A. Baron, J. A. Kanis, E. J. Orav, H. B. Staehelin, D. P. Kiel, P. Burckhardt, J. Henschkowski, D. Spiegelman, R. Li, J. B. Wong, D. Feskanich, and W. C. Willett. 2011. Milk intake and risk of hip fracture in men and women: A meta-analysis of prospective cohort studies. J. Bone Miner. Res. 26:833-839.

Bischoff-Ferrari, H. A., and H. B. Staehelin. 2008. Importance of vitamin D and calcium at older age. Int. J. Vitam. Nutr. Res. 78:286-292.

Bishop-MacDonald, H. 2005. Dairy food consumption and health: State of the science on current topics. J. Am. Coll. Nutr. 24(Suppl.):525S.

Bonjour, J.-P. 2005. Dietary protein: An essential nutrient for bone health. J. Am. Coll. Nutr. 24(Suppl. 6):526S-536S

Bonjour, J.-P., V. Benoit, O. Pourchaire, M. Ferry, B. Rousseau, and J.-C. Souberbielle. 2009. Inhibition of markers of bone resorption by consumption of vitamin $\mathrm{D}$ and calcium-fortified soft plain cheese by institutionalised elderly women. Br. J. Nutr. 102:962-966.

Bonjour, J.-P., M. Brandolini-Bunlon, Y. Boirie, F. Morel-Laporte, V. Braesco, M.-C. Bertière, and J.-C. Souberbielle. 2008. Inhibition of bone turnover by milk intake in postmenopausal women. Br. J. Nutr. 100:866-874.

Bringhurst, F. R., M. B. Demay, and H. M. Kronenberg. 2008. Hormones and disorders of mineral metabolism. Pages 1203-1268 in Williams Textbook of Endocrinology. H. M. Kronenberg, S. Melmed, K. S. Polonsky, and P. R. Larsen, ed. Saunders Elsevier, Philadelphia, PA.

Buchowski, M. S., K. C. Sowizral, F. W. Lengemann, D. Van Campen, and D. D. Miller. 1989. A comparison of intrinsic and extrinsic tracer methods for estimating calcium bioavailability to rats from dairy foods. J. Nutr. 119:228-234.

Bushinsky, D. A. 2001. Acid-base imbalance and the skeleton. Eur. J. Nutr. 40:238-244.

Cao, J. J., L. K. Johnson, and J. R. Hunt. 2011. A diet high in meat protein and potential renal acid load increases fractional calcium absorption and urinary calcium excretion without affecting markers of bone resorption or formation in postmenopausal women. J. Nutr. 141:391-397.

Cho, K., T. Cederholm, and J. Lökk. 2008. Calcium intake in elderly patients with hip fractures. Food Nutr. Res. 52:doi:10.3402/fnr. v52i0.1654.

Cochet, B., A. Jung, M. Griessen, P. Bartholdi, P. Schaller, and A. Donath. 1983. Effects of lactose on intestinal calcium absorption in normal and lactase-deficient subjects. Gastroenterology 84:935-940.

Commission of the European Union. 2008. Commission Directive 2008/100/EC of 28 October 2008 amending Council Directive 90/496/EEC on nutrition labelling for foodstuffs as regards recommended daily allowances, energy conversion factors and definitions. Official Journal of the European Union, L 285/9-12. Accessed Sep. 10, 2011. http://eur-lex.europa.eu/LexUriServ/LexUriServ.do?uri $=\mathrm{OJ}: \mathrm{L}: 2008: 285: 0009: 0012: \mathrm{EN}: \mathrm{PDF}$. 
Consensus Development Conference. 1993. Consensus Development Conference: Diagnosis, prophylaxis and treatment of osteoporosis. Am. J. Med. 94:646-650.

Cranney, A., T. Horsley, S. O'Donnell, H. Weiler, L. Puil, D. Ooi, S. Atkinson, L. Ward, D. Moher, D. Hanley, M. Fang, F. Yazdi, C. Garritty, M. Sampson, N. Barrowman, A. Tsertsvadze, and V. Mamaladze. 2007. Effectiveness and safety of vitamin D in relation to bone health. Evid. Rep. Technol. Assess. (Full Rep.) 158:1-235.

Cumming, R. G., and R. J. Klineberg. 1994. Case-control study of risk factors for hip fractures in the elderly. Am. J. Epidemiol. 139:493-503.

Daly, R. M., M. Brown, S. Bass, S. Kukuljan, and C. Nowson. 2006. Calcium and vitamin $\mathrm{D}_{3}$-fortified milk reduced bone loss at clinically relevant skeletal sites in older men: A 2-year randomized controlled trial. J. Bone Miner. Res. 21:397-405.

Daly, R. M., N. Petrass, S. Bass, and C. A. Nowson. 2008. The skeletal benefits of calcium- and vitamin $\mathrm{D}_{3}$-fortified milk are sustained in older men after withdrawal of supplementation: An 18-mo followup study. Am. J. Clin. Nutr. 87:771-777.

Donida, B. M., E. Mrak, C. Gravaghi, I. Villa, S. Cosentino, E. Zacchi, S. Perego, A. Rubinacci, A. Fiorilli, G. Tettamanti, and A. Ferraretto. 2009. Casein phosphopeptides promote calcium uptake and modulate differentiation pathway in human primary osteoblast-like cells. Peptides 30:2233-2241.

Du, M., Y. Kong, C. Wang, H. Gao, X. Han, H. Yi, and L. Zhang. 2011a. Short communication: Proteins in heat-processed skim milk powder have no positive effects on bone loss of ovariectomized rats. J. Dairy Sci. 94:2771-2774.

Du, M., W. Xu, H. Yi, X. Han, C. Wang, and L. Zhang. 2011b. Protective effects of bovine colostrum acid proteins on bone loss of ovariectomized rats and the ingredients identification. Mol. Nutr. Food Res. 55:220-228.

EFSA (European Food Safety Authority). 2009. Scientific Opinion on the substantiation of health claims related to calcium and growth, development and maintenance of the normal structure and function of bones and teeth (ID 224, 230, 231, 354, 3099), muscle function and neurotransmission (ID 226, 227, 230, 235), blood coagulation (ID 230, 236), energy-yielding metabolism (ID 234), normal function of digestive enzymes (ID 355), and maintenance of a normal blood pressure (ID 225, 385, 1419) pursuant to Article 13(1) of Regulation (EC) No 1924/2006. EFSA J. 7:1210.

Esterle, L., J. P. Sabatier, F. Guillon-Metz, O. Walrant-Debray, G. Guaydier-Souquières, F. Jehan, and M. Garabédian. 2009. Milk, rather than other foods, is associated with vertebral bone mass and circulating IGF-1 in female adolescents. Osteoporos. Int. 20:567-575.

European Commission. 1999. Evaluation of the School Milk Measure-Final Report

European Commission. 2006. Milk and dairy products in the European Union-August 2006. Office for Official Publications of the European Communities, Luxembourg.

Fardellone, P., F.-E. Cotté, C. Roux, E. Lespessailles, F. Mercier, and A.-F. Gaudin. 2010. Calcium intake and the risk of osteoporosis and fractures in French women. Joint Bone Spine 77:154-158.

Favus, M. J., and E. Angeid-Backman. 1984. Effects of lactose on calcium absorption and secretion by rat ileum. Am. J. Physiol. 246:G281-G285

Feskanich, D., W. C. Willett, and G. A. Colditz. 2003. Calcium, vitamin D, milk consumption, and hip fractures: A prospective study among postmenopausal women. Am. J. Clin. Nutr. 77:504-511.

Feskanich, D., W. C. Willett, M. J. Stampfer, and G. A. Colditz. 1997. Milk, dietary calcium, and bone fractures in women: A 12-year prospective study. Am. J. Public Health 87:992-997.

FitzGerald, R. J. 1998. Potential uses of caseinophosphopeptides. Int. Dairy J. 8:451-457.

Francis, R. M., F. H. Anderson, S. Patel, O. Sahota, and T. P. van Staa. 2006. Calcium and vitamin D in the prevention of osteoporotic fractures. QJM 99:355-363.

Gennari, C. 2001. Calcium and vitamin D nutrition and bone disease of the elderly. Public Health Nutr. 4:547-559.
Gerber, H. W., and R. Jost. 1986. Casein phosphopeptides: Their effect on calcification of in vitro cultured embryonic rat bone. Calcif. Tissue Int. 38:350-357.

Guéguen, L., and A. Pointillart. 2000. The bioavailability of dietary calcium. J. Am. Coll. Nutr. 19(Suppl. 2):119S-136S.

Hawker, G. A., S. Forsmo, S. M. Cadarette, B. Schei, S. B. Jaglal, L. Forsén, and A. Langhammer. 2002. Correlates of forearm bone mineral density in young Norwegian women: The Nord-Trøndelag health study. Am. J. Epidemiol. 156:418-427.

Heaney, R. P. 1996. Calcium. Pages 1007-1018 in Principles of Bone Biology. J. P. Bilezikian, L. G. Raisz, and G. A. Rodan, ed. Academic Press, New York, NY.

Heaney, R. P. 2000a. Calcium, dairy products and osteoporosis. J. Am. Coll. Nutr. 19(Suppl.):83S-99S.

Heaney, R. P. 2000b. Peak bone mass. Osteoporos. Int. 11:985-1009

Heaney, R. P. 2009. Dairy and bone health. J. Am. Coll. Nutr. 28(Suppl. 1):82S-90S.

Heaney, R. P., and C. M. Weaver. 2005. Newer perspectives on calcium nutrition and bone quality. J. Am. Coll. Nutr. 24:574S-581S.

Heaney, R. P., C. M. Weaver, and R. R. Recker. 1988. Calcium absorbability from spinach. Am. J. Clin. Nutr. 47:707-709.

Henry, H. L., R. Bouillon, A. W. Norman, J. C. Gallagher, P. Lips, R. P. Heaney, R. Vieth, J. M. Pettifor, B. Dawson-Hughes, C. J. Lamberg-Allardt, and P. R. Ebeling. 2010. 14th Vitamin D Workshop consensus on vitamin D nutritional guidelines. J. Steroid Biochem. Mol. Biol. 121:4-6.

Ho-Pham, L. T., N. D. Nguyen, and T. V. Nguyen. 2009. Effect of vegetarian diets on bone mineral density: a Bayesian meta-analysis. Am. J. Clin. Nutr. 90:943-950.

Holick, M. F. 2007. Vitamin D deficiency. N. Engl. J. Med. 357:266281.

Huth, P. J., D. B. DiRienzo, and G. D. Miller. 2006. Major scientific advances with dairy foods in nutrition and health. J. Dairy Sci. 89:1207-1221.

Itabashi, A. 2006. Prevention of osteoporosis by foods and dietary supplements. Milk basic protein (MBP) increases bone density in young adult women and perimenopausal women. Clin. Calcium $16: 1632-1638$

IDF (International Dairy Federation). 2011. Italian Dairy industry an overview. Accessed Feb. 20, 2011. http://www.wds2011.com/TextFlowPage.php?ID $=375$

Jackson, R. D., A. Z. LaCroix, M. Gass, R. B. Wallace, J. Robbins, C E. Lewis, T. Bassford, S. A. A. Beresford, H. R. Black, P. Blanchette, D. E. Bonds, R. L. Brunner, R. G. Brzyski, B. Caan, J. A Cauley, R. T. Chlebowski, S. R. Cummings, I. Granek, J. Hays, G. Heiss, S. L. Hendrix, B. V. Howard, J. Hsia, F. A. Hubbell, K. C. Johnson, H. Judd, J. M. Kotchen, L. H. Kuller, R. D. Langer, N. L. Lasser, M. C. Limacher, S. Ludlam, J. E. Manson, K. L. Margolis, J. McGowan, J. K. Ockene, M. J. O'Sullivan, L. Phillips, R. L. Prentice, G. E. Sarto, M. L. Stefanick, L. Van Horn, J. Wactawski-Wende, E. Whitlock, G. L. Anderson, A. R. Assaf, and D. Barad. 2006. Calcium plus vitamin D supplementation and the risk of fractures. N. Engl. J. Med. 354:669-683.

Johnell, O., and J. A. Kanis. 2004. An estimate of the worldwide prevalence, mortality and disability associated with hip fractures. Osteoporos. Int. 15:897-902.

Johnell, O., and J. A. Kanis. 2005. Epidemiology of osteoporotic fractures. Osteoporos. Int. 16(Suppl. 2):S3-S7.

Kalkwarf, H. J., J. C. Khoury, and B. P. Lanphear. 2003. Milk intake during childhood and adolescence, adult bone density, and osteoporotic fractures in US women. Am. J. Clin. Nutr. 77:257-265.

Kanis, J. A., H. Johansson, A. Oden, C. De Laet, O. Johnell, J. A. Eisman, E. Mc Closkey, D. Mellstrom, H. Pols, J. Reeve, A. Silman, and A. Tenenhouse. 2005. A meta-analysis of milk intake and fracture risk: Low utility for case finding. Osteoporos. Int. 16:799-804.

Kardinaal, A. F. M., S. Ando, P. Charles, J. Charzewska, M. Rotily, K. Väänänen, A. M. J. Van Erp-Baart, J. Heikkinen, J. Thomsen, M. Maggiolini, A. Deloraine, E. Chabros, R. Juvin, and G. Schaafsma. 1999. Dietary calcium and bone density in adolescent girls and young women in Europe. J. Bone Miner. Res. 14:583-592. 
Kärkkäinen, M., M. Tuppurainen, K. Salovaara, L. Sandini, T. Rikkonen, J. Sirola, R. Honkanen, J. Jurvelin, E. Alhava, and H. Kröger. 2010. Effect of calcium and vitamin D supplementation on bone mineral density in women aged 65-71 years: A 3-year randomized population-based trial (OSTPRE-FPS). Osteoporos. Int. 21:2047-2055.

Kaune, R. 1996. Mechanisms of intestinal calcium absorption and availability of dietary calcium in pigs. Dtsch. Tierarztl. Wochenschr. 103:215-218.

Kruger, M. C., C. L. Booth, J. Coad, L. M. Schollum, B. Kuhn-Sherlock, and M. J. Shearer. 2006. Effect of calcium fortified milk supplementation with or without vitamin $\mathrm{K}$ on biochemical markers of bone turnover in premenopausal women. Nutrition 22:1120-1128.

Kruger, M. C., L. M. Schollum, B. Kuhn-Sherlock, A. Hestiantoro, P. Wijanto, J. Li-Yu, I. Agdeppa, J. M. Todd, and R. Eastell. 2010. The effect of a fortified milk drink on vitamin D status and bone turnover in post-menopausal women from South East Asia. Bone 46:759-467.

Lanham-New, S. A. 2008. Importance of calcium, vitamin D and vitamin K for osteoporosis prevention and treatment. Proc. Nutr. Soc. 67:163-176.

Lanou, A. J. 2009. Should dairy be recommended as part of a healthy vegetarian diet? Counterpoint. Am. J. Clin. Nutr. 89:1638S$1642 \mathrm{~S}$.

Lanou, A. J., S. E. Berkow, and N. D. Barnard. 2005. Calcium, dairy products, and bone health in children and young adults: A reevaluation of the evidence. Pediatrics 115:736-743.

Larson, N. I., D. Neumark-Sztainer, L. Harnack, M. Wall, M. Story, and M. E. Eisenberg. 2009. Calcium and dairy intake: Longitudinal trends during the transition to young adulthood and correlates of calcium intake. J. Nutr. Educ. Behav. 41:254-260.

Leclercq, C., D. Arcella, R. Piccinelli, S. Sette, C. Le Donne, and A. Turrini. 2009. The Italian National Food Consumption Survey INRAN-SCAI 2005-06: Main results in terms of food consumption. Public Health Nutr. 12:2504-2532.

Lee, C., and D. S. Majka. 2006. Is calcium and vitamin D supplementation overrated? J. Am. Diet. Assoc. 106:1032-1034.

Lekamwasam, S., L. Wijayaratne, M. Rodrigo, and U. Hewage. 2009. Prevalence and determinants of osteoporosis among men aged 50 years or more in Sri Lanka: A community-based cross-sectional study. Arch. Osteoporos. 4:79-84.

Lindsay, R., and J. Nieves. 1994. Milk and bones. BMJ 308:930.

López-Huertas, E., B. Teucher, J. J. Boza, A. Martínez-Férez, G. Majsak-Newman, L. Baró, J. J. Carrero, M. González-Santiago, J. Fonollá, and S. Fairweather-Tait. 2006. Absorption of calcium from milks enriched with fructo-oligosaccharides, caseinophosphopeptides, tricalcium phosphate, and milk solids. Am. J. Clin. Nutr. 83:310-316.

Mangano, K. M., S. J. Walsh, K. L. Insogna, A. M. Kenny, and J. E. Kerstetter. 2011. Calcium intake in the United States from dietary and supplemental sources across adult age groups: New estimates from the National Health and Nutrition Examination Survey 2003-2006. J. Am. Diet. Assoc. 111:687-695.

Manios, Y., G. Moschonis, D. B. Panagiotakos, P. Farajian, G. Trovas, and G. P. Lyritis. 2009. Changes in biochemical indices of bone metabolism in post-menopausal women following a dietary intervention with fortified dairy products. J. Hum. Nutr. Diet. 22:156-165.

Manios, Y., G. Moschonis, G. Trovas, and G. P. Lyritis. 2007. Changes in biochemical indexes of bone metabolism and bone mineral density after a 12-mo dietary intervention program: The Postmenopausal Health Study. Am. J. Clin. Nutr. 86:781-789.

Manzi, P., S. Marconi, M. G. Di Costanzo, and L. Pizzoferrato. 2007. Composizione di formaggi DOP italiani. La Rivista di Scienza dell'Alimentazione 36:9-22.

Melhus, H., G. Snellman, R. Gedeborg, L. Byberg, L. Berglund, H. Mallmin, P. Hellman, R. Blomhoff, E. Hagström, J. Ärnlöv, and K. Michaëlsson. 2010. Plasma 25-hydroxyvitamin D levels and fracture risk in a community-based cohort of elderly men in Sweden. J. Clin. Endocrinol. Metab. 95:2637-2645.
Morita, Y., A. Ono, A. Serizawa, K. Yogo, N. Ishida-Kitagawa, T. Takeya, and T. Ogawa. 2011. Purification and identification of lactoperoxidase in milk basic protein as an inhibitor of osteoclastogenesis. J. Dairy Sci. 94:2270-2279.

Moschonis, G., I. Katsaroli, G. P. Lyritis, and Y. Manios. 2010. The effects of a 30-month dietary intervention on bone mineral density: The Postmenopausal Health Study. Br. J. Nutr. 104:100-107.

Moschonis, G., and Y. Manios. 2006. Skeletal site-dependent response of bone mineral density and quantitative ultrasound parameters following a 12-month dietary intervention using dairy products fortified with calcium and vitamin D: The Postmenopausal Health Study. Br. J. Nutr. 96:1140-1148.

Murray, T. M. 1996. Calcium nutrition and osteoporosis. CMAJ 155:935-939.

Nguyen, T. V., J. R. Center, and J. A. Eisman. 2000. Osteoporosis in elderly men and women: Effects of dietary calcium, physical activity, and body mass index. J. Bone Miner. Res. 15:322-331.

Nicklas, T. A, C. E. O'Neil, and V. L. Fulgoni III. 2009. The role of dairy in meeting the recommendations for shortfall nutrients in the American diet. J. Am. Coll. Nutr. 28(Suppl. 1):73S-81S.

O'Connor, C. 1993. Traditional Cheesemaking Manual. International Livestock Centre for Africa (ILCA), Addis Ababa, Ethiopia.

Palacios, S., C. Castelo-Branco, I. Cifuentes, S. von Helde, L. Baró, C. Tapia-Ruano, C. Menéndez, and C. Rueda. 2005. Changes in bone turnover markers after calcium-enriched milk supplementation in healthy postmenopausal women: A randomized, double-blind, prospective clinical trial. Menopause 12:63-68.

Pennington, J. A. T. 1994. Bowes and Church's Food Values of Portions Commonly Used. 16th ed. J. B. Lippincott \& Co., Philadelphia, PA.

Peters, B. S., and L. A. Martini. 2010. Nutritional aspects of the prevention and treatment of osteoporosis. Arq. Bras. Endocrinol. Metabol. 54:179-185.

Priemel, M., C. von Domarus, T. O. Klatte, S. Kessler, J. Schlie, S. Meier, N. Proksch, F. Pastor, C. Netter, T. Streichert, K. Püschel, and M. Amling. 2010. Bone mineralization defects and vitamin D deficiency: Histomorphometric analysis of iliac crest bone biopsies and circulating 25-hydroxyvitamin D in 675 patients. J. Bone Miner. Res. 25:305-312.

Rabenda, V., O. Bruyère, and J.-Y. Reginster. 2011. Relationship between bone mineral density changes and risk of fractures among patients receiving calcium with or without vitamin D supplementation: A meta-regression. Osteoporos. Int. 22:893-901.

Raisz, L. G. 2005. Pathogenesis of osteoporosis. J. Clin. Invest. 115:3318-3325.

Recker, R. R., K. M. Davies, S. M. Hinders, R. P. Heaney, M. R. Stegman, and D. B. Kimmel. 1992. Bone gain in young adult women. JAMA 268:2403-2408.

Reeves, R. E., and N. G. Latour. 1958. Calcium phosphate sequestering phosphopeptides from casein. Science 128:472.

Rizzoli, R., M. L. Bianchi, M. Garabédian, H. A. McKay, and L. A. Moreno. 2010. Maximizing bone mineral mass gain during growth for the prevention of fractures in the adolescents and the elderly. Bone 46:294-305.

Ross, A. C., J. E. Manson, S. A. Abrams, J. F. Aloia, P. M. Brannon, S. K. Clinton, R. A. Durazo-Arvizu, J. C. Gallagher, R. L. Gallo, G. Jones, C. S. Kovacs, S. T. Mayne, C. J. Rosen, and S. A. Shapses. 2011. The 2011 report on dietary reference intakes for calcium and vitamin D from the Institute of Medicine: What clinicians need to know. J. Clin. Endocrinol. Metab. 96:53-58.

Roux, C., H. A. Bischoff-Ferrari, S. E. Papapoulos, A. E. de Papp, J. A. West, and R. Bouillon. 2008. New insights into the role of vitamin $\mathrm{D}$ and calcium in osteoporosis management: An expert roundtable discussion. Curr. Med. Res. Opin. 24:1363-1370.

Ruffing, J. A., F. Cosman, M. Zion, S. Tendy, P. Garrett, R. Lindsay, and J. W. Nieves. 2006. Determinants of bone mass and bone size in a large cohort of physically active young adult men. Nutr. Metab. (Lond.) 3:14 doi:10.1186/1743-7075-3-14.

Sette, S., C. Le Donne, R. Piccinelli, D. Arcella, A. Turrini, and C. Leclercq. 2010. The third Italian National Food Consumption 
Survey, INRAN-SCAI 2005-06-Part 1: Nutrient intakes in Italy. Nutr. Metab. Cardiovasc. Dis. doi:10.1016/j.numecd.2010.03.001.

Soroko, S., T. L. Holbrook, S. Edelstein, and E. Barrett-Connor. 1994. Lifetime milk consumption and bone mineral density in older women. Am. J. Public Health 84:1319-1322.

Sowers, M. R., and D. A. Galuska. 1993. Epidemiology of bone mass in premenopausal women. Epidemiol. Rev. 15:374-398.

Spangler, M., B. B. Phillips, M. B. Ross, and K. G. Moores. 2011. Calcium supplementation in postmenopausal women to reduce the risk of osteoporotic fractures. Am. J. Health Syst. Pharm. 68:309-318.

Straub, D. A. 2007. Calcium supplementation in clinical practice: A review of forms, doses, and indications. Nutr. Clin. Pract. $22: 286-296$.

Sunyecz, J. A. 2008. The use of calcium and vitamin D in the management of osteoporosis. Ther. Clin. Risk Manag. 4:827-836.

Thorpe, M. P., and E. M. Evans. 2011. Dietary protein and bone health: Harmonizing conflicting theories. Nutr. Rev. 69:215-230.

Toba, Y., Y. Takada, J. Yamamura, M. Tanaka, Y. Matsuoka, H. Kawakami, A. Itabashi, S. Aoe, and M. Kumegawa. 2000. Milk basic protein: A novel protective function of milk against osteoporosis. Bone 27:403-408.

Tucker, K. L. 2003. Does milk intake in childhood protect against later osteoporosis? Am. J. Clin. Nutr. 77:10-11.

Tucker, K. L. 2009. Osteoporosis prevention and nutrition. Curr. Osteoporos. Rep. 7:111-117.

Tulipano, G., O. Bulgari, S. Chessa, A. Nardone, D. Cocchi, and A. Caroli. 2010. Direct effects of casein phosphopeptides on growth and differentiation of in vitro cultured osteoblastic cells (MC3T3E1). Regul. Pept. 160:168-174.

Uenishi, K., H. Ishida, Y. Toba, S. Aoe, A. Itabashi, and Y. Takada. 2007. Milk basic protein increases bone mineral density and improves bone metabolism in healthy young women. Osteoporos. Int. $18: 385-390$.

USDA. 2005. Dietary Guidelines for Americans. US Department of Health and Human Services 2005. Accessed Feb. 20, 2011. http:// health.gov/dietaryguidelines.
USDA and US Department of Health and Human Services. 2010. Dietary Guidelines for Americans. 7th ed. US Government Printing Office, Washington, DC.

van der Hee, R. M., S. Miret, M. Slettenaar, G. S. M. J. E. Duchateau, A. G. Rietveld, J. E. Wilkinson, P. J. Quail, M. J. Berry, J. R. Dainty, B. Teucher, and S. J. Fairweather-Tait. 2009. Calcium absorption from fortified ice cream formulations compared with calcium absorption from milk. J. Am. Diet. Assoc. 109:830-835.

Varenna, M., L. Binelli, S. Casari, F. Zucchi, and L. Sinigaglia. 2007. Effects of dietary calcium intake on body weight and prevalence of osteoporosis in early postmenopausal women. Am. J. Clin. Nutr. 86:639-644.

Wang, Y.-F., J.-S. Chiu, M.-H. Chuang, J.-E. Chiu, and C.-L. Lin. 2008. Bone mineral density of vegetarian and non-vegetarian adults in Taiwan. Asia Pac. J. Clin. Nutr. 17:101-106.

Weaver, C. M. 2008. The role of nutrition on optimizing peak bone mass. Asia Pac. J. Clin. Nutr. 17:135-137.

Weaver, C. M. 2009. Should dairy be recommended as part of a healthy vegetarian diet? Point. Am J. Clin. Nutr. 89:1634S-1637S.

Weaver, C. M., B. R. Martin, J. S. Ebner, and C. A. Kruger. 1987. Oxalic acid decreases calcium absorption in rats. J. Nutr. 117:19031906.

Weaver, C. M., and K. L. Plawecki. 1994. Dietary calcium: Adequacy of a vegetarian diet. Am. J. Clin. Nutr. 59(Suppl.):1238S-1241S

Weinsier, R. L., and C. L. Krumdieck. 2000. Dairy foods and bone health: Examination of the evidence. Am. J. Clin. Nutr. 72:681689.

WHO/FAO (World Health Organization/Food and Agriculture Organization). 2003. Diet, Nutrition and the Prevention of Chronic Diseases. Joint WHO/FAO Expert Consultation, Geneva, Switzerland. WHO Technical Report Series 916. Geneva, Switzerland. Accessed Sep. 10, 2011. http://whqlibdoc.who.int/trs/who_trs_916. pdf.

Yamamura, J., S. Aoe, Y. Toba, M. Motouri, H. Kawakami, M. Kumegawa, A. Itabashi, and Y. Takada. 2002. Milk basic protein (MBP) increases radial bone mineral density in healthy adult women. Biosci. Biotechnol. Biochem. 66:702-704. 